\title{
A ALTA DAS COMMODITIES AGRÍCOLAS E O ESTABELECIMENTO DO MILAGRINHO NA ECONOMIA BRASILEIRA DO GOVERNO LULA
}

\author{
THE RISE OF AGRICULTURAL COMMODITIES AND THE ESTABLISHMENT \\ OF THE LITTLE MIRACLE IN THE BRAZILIAN ECONOMY DURING LULA'S \\ GOVERNMENT
}

DOI: 10.5380/cg.v9i2.75712

\author{
Igor Palma Barbosa ${ }^{1}$
}

\begin{abstract}
Resumo
O efeito positivo da alta nos preços das commodities agrícolas não é suficiente para explicar a totalidade dos efeitos positivos trazidos pelo "Milagrinho" promovido pelo governo Lula (2003-2010). A maior entrada de divisas e a formação de reservas cambiais via comércio internacional sedimentaram, no primeiro momento, as condições para a dinamização do mercado interno. O setor agrícola, por sua vez, tem sua importância confirmada não só pelos indicadores econômicos como também pela diplomacia comercial da administração petista em foros multilaterais internacionais, como é o caso da atuação brasileira na Rodada Doha da Organização Mundial do Comércio (OMC). Com o objetivo de entender a conexão entre o cenário externo otimista para as economias exportadoras de commodities e seu impacto para as decisões políticas do governo Lula, realizou-se um estudo de caso sobre a administração lulista e foi verificado que políticas de estímulo ao consumo e investimentos públicos atrelados a facilitação do acesso ao crédito, valorização do salário mínimo e criação de programas de transferência de renda, deram a tônica aos avanços sociais alcançados, principalmente, no segundo mandato do governo Lula.
\end{abstract}

Palavras-Chave: Commodities; Exportações; Crescimento; Mercados.

\begin{abstract}
The positive effect of the rise in the prices of agricultural commodities is not enough to explain the totality of the positive effects brought about by the "Milagrinho" promoted by the Lula government (2003-2010). The greater inflow of foreign exchange and the formation of foreign exchange reserves via international trade sedimented the conditions for the dynamization of the domestic market. The agricultural sector, in turn, has its importance confirmed not only by the economic indicators but also by the commercial diplomacy of the PT administration in international multilateral forums, as is the case of Brazilian action in the Doha Round of the World Trade Organization (WTO). In order to understand the connection between the optimistic external scenario for commodity-exporting economies and its impact on the political decisions of the Lula government, a case study was carried out on the Lula's administration and it was verified that policies to stimulate consumption and public investments linked to facilitating access to credit, appreciation of the minimum wage and the creation of income transfer programs emphasized the social advances achieved, mainly in the second term of the Lula government.
\end{abstract}

Keywords: Commodities; Exportations; Growth; Markets.

\footnotetext{
${ }^{1}$ Mestrando em Ciência Política e Relações Internacionais pela Universidade Federal da Paraíba (UFPB) e bacharel em Relações Internacionais pela mesma instituição. E-mail: igorpalmab12@gmail.com. ORCID: https://orcid.org/0000-0002-6293-1279.
} 


\section{INTRODUÇÃO}

O crescimento acelerado da primeira década dos anos 2000 foi fortemente marcado pela dinamização de uma atmosfera internacional mais favorável a exportação de commodities agrícolas e minerais. O largo crescimento chinês e sua demanda por esses produtos foram responsáveis por proporcionar saltos positivos nas balanças comerciais de muitos países latino-americanos que sempre se posicionaram historicamente como grandes exportadores do setor primário. O Brasil soube bem surfar nessa onda e aproveitou para desenvolver novos direcionamentos macroeconômicos, que permitiram a dinamização de seu mercado interno.

O governo Lula (2003-2010) ficou marcado pelo ineditismo de conseguir vincular crescimento econômico a demandas sociais. A expansão do setor primário exportador permitiu a criação de reservas cambiais com a ampla entrada de divisas via comércio internacional, dando as condições de sustento inicial para suas políticas sociais. No que se refere ao setor agrícola, as atuações diplomáticas e discursivas do presidente se alinharam positivamente aos indicadores econômicos. A participação brasileira na Rodada Doha da Organização Mundial do Comércio (OMC) junto ao G20 comercial atesta a defesa e a importância do setor para o país.

O estabelecimento do que a economista Laura Carvalho chamou de "Milagrinho", via dinamização do mercado interno em 2006, em muito se beneficiou desse primeiro momento de crescimento dos preços das commodities. Dada a condição externa positiva, tomou-se a decisão política de aumentar os investimentos públicos, o acesso ao crédito, a distribuição de renda nas camadas mais baixas, o estímulo ao consumo e uma nova configuração para um mercado de trabalho formalizado, que garantiram o sustento de saldos positivos no desenvolvimento social e econômico do país. Com altas reservas cambiais e real apreciado, coube ao setor industrial pagar o preço mais alto por essa política, que privilegiou muito mais os setores de serviços e construção civil.

Diante do exposto, esse artigo se propõe a estabelecer o link entre o cenário externo otimista para as economias exportadoras de commodities e as decisões políticas do governo Lula que alcançaram a melhoria de indicadores sociais via dinamização do mercado interno. Para tanto, foi realizado um estudo de caso da administração lulista a fim de perceber como os ganhos alcançados pelo crescimento do comércio agrícola tem influenciado positivamente para o novo direcionamento macroeconômico de seu governo. Dividido em 3 grandes seções, na primeira serão tratadas as condições econômicas favoráveis vinculadas ao cenário externo e os indicadores positivos alcançados pelo Brasil nesse período. Na segunda, será explanado o que foi a Rodada Doha da OMC e demonstrar como o alinhamento brasileiro à pauta agrícola fez parte da diplomacia comercial da administração petista nos foros internacionais multilaterais. Por fim, no último tópico, serão abordadas as condições que permitiram a configuração do "Milagrinho", bem como suas principais características e efeitos. 


\section{ANOS 2000 E O BOOM DAS COMMODITIES}

Os anos 2000 ficaram marcados por uma nova onda de crescimento econômico puxada pelas exportações das commodities agrícolas e minerais brasileiras. O alinhamento Sul-Sul, incentivado e oficializado pelo governo Lula a partir de 2003, encontrou novos mercados receptores dessas mercadorias dentro de um cenário internacional favorável ao comércio dos produtos in natura. $\mathrm{O}$ estreitamento dos laços com a China, por exemplo, trouxe à balança comercial brasileira importantes superávits, capazes de impulsionar a entrada de um maior volume de divisas e diminuir os efeitos do constrangimento externo para arcar com os custos de políticas públicas sociais a partir do desenvolvimento do mercado interno (SILVA e LOPREATO, 2017).

Por sua vez, a elevação dos preços das commodities também constituiu fator de grande importância para explicar a rentabilidade das exportações brasileiras na primeira década dos anos 2000. Observe os dados a seguir relacionados ao índice de preços dessas mercadorias.

TABELA 1 - TAXA DE CRESCIMENTO DOS PREÇOS DAS COMMODITIES
\begin{tabular}{c|c}
\hline EM RELAÇÃO AO ANO ANTERIOR (EM \%). \\
\hline Ano & Taxa de Crescimento \\
\hline 2000 & 25,86 \\
\hline 2001 & $-6,95$ \\
\hline 2002 & $-0,61$ \\
\hline 2003 & 17,63 \\
\hline 2004 & 20,52 \\
\hline 2005 & 23,40 \\
\hline 2006 & 16,87 \\
\hline 2007 & 13,06 \\
\hline 2008 & 26,36 \\
\hline 2009 & $-28,36$ \\
\hline 2010 & 25,03 \\
\hline 2011 & 24,88 \\
\hline 2012 & $-4,41$ \\
\hline 2013 & $-3,23$ \\
\hline 2014 & $-5,73$ \\
\hline 2015 & $-31,95$ \\
\hline
\end{tabular}

Fonte: Elaboração própria a partir da base de dados do FMI (2020).

O saldo positivo persistente em quase todo o período de administração petista do presidente Lula (2003-2010) trouxe dinamicidade ao setor agroexportador. Tais efeitos foram responsáveis por acalorar debates sobre uma possível desindustrialização da economia brasileira via o que se convencionou chamar de "doença holandesa” (SILVA e CUNHA, 2016).

O termo doença holandesa é usado para definir uma situação de grande fluxo de exportações de recursos naturais capazes de sustentar um processo de apreciação cambial. O efeito disso para o setor industrial pode trazer uma espécie de estrangulamento pela demanda, visto que os incentivos ao investimento em setores com maior potencial de transformação encontram-se inviabilizados. A 
competitividade de seus produtos industriais também pode ser prejudicada com um câmbio apreciado, uma vez que provoca a elevação de seus preços. A sustentação dessa situação, no entanto, se deu com a rentabilidade das exportações agrícolas e minerais (WASQUES e TRINTIN, 2018). No que cerne ao setor agrícola, principal objeto de estudo desse artigo, observe na tabela abaixo como os dados confirmam o seu impacto para o crescimento econômico alcançado no período quando comparado com os referentes ao setor de manufaturados.

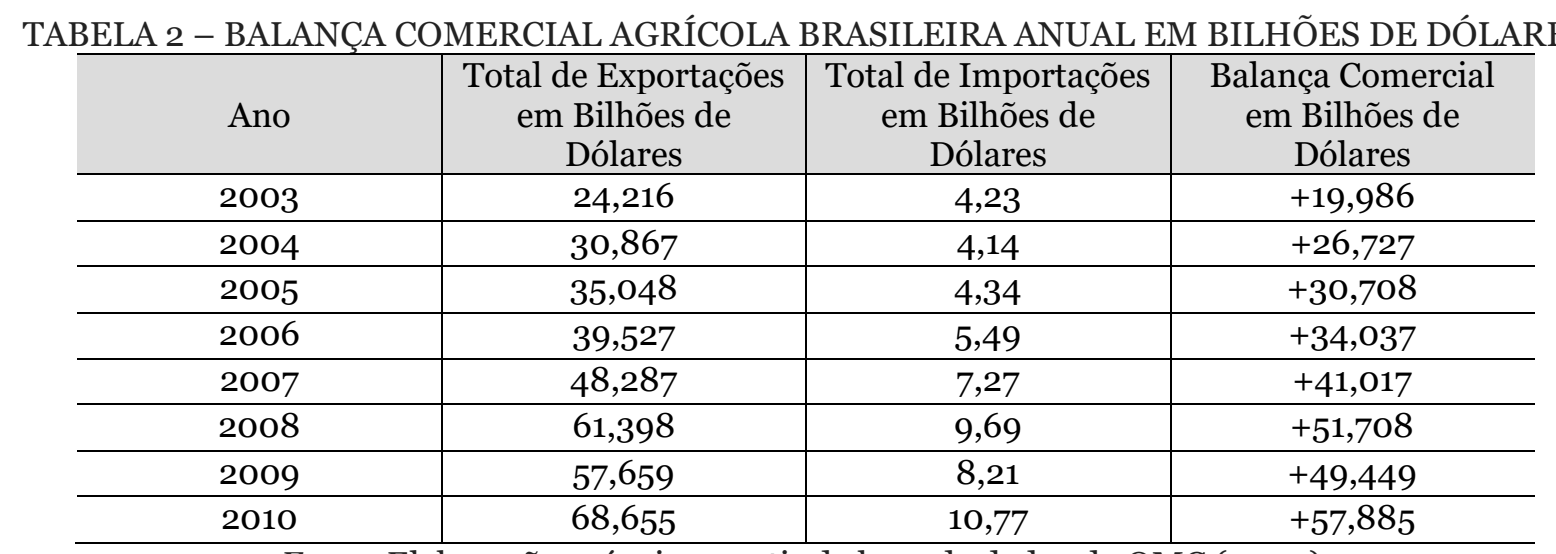

Fonte: Elaboração própria a partir da base de dados da OMC (2020).

TABELA 3 - BALANÇA COMERCIAL DE MANUFATURADOS BRASILEIRA ANUAL EM BILHÕES DE DÓLARES

\begin{tabular}{c|c|c|c}
\hline Ano & $\begin{array}{c}\text { Total de Exportações } \\
\text { em Bilhões de } \\
\text { Dólares }\end{array}$ & $\begin{array}{c}\text { Total de Importações } \\
\text { em Bilhões de } \\
\text { Dólares }\end{array}$ & $\begin{array}{c}\text { Balança Comercial } \\
\text { em Bilhões de } \\
\text { Dólares }\end{array}$ \\
\hline 2003 & 37,293 & 35,052 & $+2,241$ \\
\hline 2004 & 50,763 & 44,816 & $+5,947$ \\
\hline 2005 & 61,769 & 52,949 & $+8,82$ \\
\hline 2006 & 68,411 & 64,115 & $+4,296$ \\
\hline 2007 & 74,903 & 77,118 & $-2,215$ \\
\hline 2008 & 86,405 & 121,732 & $-35,327$ \\
\hline 2009 & 58,141 & 96,908 & $-38,767$ \\
\hline 2010 & 71,112 & 134,688 & $-63,576$ \\
\hline
\end{tabular}

Fonte: Elaboração própria a partir da base de dados da OMC (2020).

TABELA 4 - PIB AGRÍCOLA BRASILEIRO ANUAL EM BILHÕES DE DÓLARES

\begin{tabular}{c|c}
\hline Ano & $\begin{array}{c}\text { PIB Agrícola em } \\
\text { Bilhões de Dólares }\end{array}$ \\
\hline 2003 & 34,4 \\
\hline 2004 & 37,9 \\
\hline 2005 & 41,4 \\
\hline 2006 & 48,4 \\
\hline 2007 & 61,7 \\
\hline 2008 & 77,4 \\
\hline 2009 & 74,6 \\
\hline 2010 & 90,9 \\
\hline
\end{tabular}

Fonte: Elaboração própria a partir da base de dados do Banco Mundial (2020). 
TABELA 5 - TAXA DE CRESCIMENTO ANUAL DO PIB BRASILEIRO (EM \%)

\begin{tabular}{c|c}
\hline Ano & $\begin{array}{c}\text { Total de Exportações } \\
\text { em Bilhões de } \\
\text { Dólares }\end{array}$ \\
\hline 2003 & 1,1 \\
\hline 2004 & 5,8 \\
\hline 2005 & 3,2 \\
\hline 2006 & 4 \\
\hline 2007 & 5,1 \\
\hline 2008 & 6,1 \\
\hline 2009 & $-0,1$ \\
\hline 2010 & 7,5 \\
\hline
\end{tabular}

Fonte: Elaboração própria a partir da base de dados do Banco Mundial (2020).

Tais condicionalidades atestam a sensibilidade que as economias periféricas apresentam aos movimentos cíclicos internacionais. O começo dos anos 2000 foi marcado por um forte período de crise e retração dos fluxos de créditos internacionais. A crise da Argentina e os conflitos no Oriente Médio traziam impactos à confiabilidade dos mercados em toda a América Latina. O atentado aos Estados Unidos em 2001 intensificou ainda mais as incertezas e retração de seu comércio. Somente em 2003 sinais de melhora foram observados. Com taxas de juros mais baixas nos Estados Unidos e spreads bancários menores para os mercados emergentes, muitos desses países se aventuraram em estratégias de estímulo ao consumo e desenvolvimento a partir da criação de condições favoráveis no mercado interno (SERRANO e SUMMA, 2015).

Para a economia brasileira, conforme os dados expostos acima, o impacto dessa melhora a partir de 2003 foi muito positivo. Aliado ao aumento do comércio Sul-Sul e da valorização dos preços das commodities, o crescimento do PIB brasileiro no período foi influenciado significativamente pelas exportações como fonte de demanda agregada. Além disso, a maior entrada de divisas e acumulação das reservas cambiais via comércio viabilizou a diminuição das restrições externas ao desenvolvimento e à expansão do mercado interno (SILVA e CUNHA, 2016). A importância de uma balança comercial superavitária também foi marca discursiva do presidente Lula em seu período de administração. A diplomacia comercial de seu governo em esferas multilaterais como a Organização Mundial do Comércio (OMC) foi marcada por uma defesa ostensiva da liberalização do comércio agrícola. O caso da Rodada Doha e sua negociação junto ao G2o comercial representam um exemplo claro disso e será objeto de estudo da próxima seção.

\section{ORGANIZAÇÃo MUNDIAL DO COMÉRCIO, RODADA DOHA E DIPLOMACIA COMERCIAL}

O fechamento do Acordo sobre Agricultura (AsA) em 1994 e a criação da Organização Mundial do Comércio (OMC) em 1995 sinalizaram um importante avanço para as discussões ligadas 
a liberalização agrícola dentro do Sistema Multilateral de Comércio (SMC). A inclusão oficial e inédita do tema agrícola no texto da organização se propôs à regular três grandes áreas: acesso a mercados, subsídios às exportações e subsídios internos. Essas provisões, no entanto, não foram suficientes para corrigir as desvantagens históricas impostas aos países em desenvolvimento (PED) e menos desenvolvidos. O tradicionalismo herdado ainda pelo Acordo Geral de Tarifas e Comércio (GATT) privilegiava os interesses dos países desenvolvidos (PD) ao priorizar a liberalização e tarifação de itens manufaturados e defender uma política protecionista para os itens agrícolas (RAMANZINI JÚNIOR, 2012; COSKERAN, KIM e NARLIKAR, 2012; WILKINSON, 2014a).

No que cerne as provisões do acordo sobre o acesso a mercados ficou estabelecido que todas as barreiras não tarifárias deveriam se transformar em tarifas ad valorem e criou-se um Mecanismo de Salvaguarda Especial (SSP) de caráter transitório, dando aos países o poder de acrescentar impostos para proteger seus mercados internos em caso de queda expressiva no preço de alguma commodity ou surto importador de um produto específico. Em relação aos subsídios à exportação, ficou acordada sua redução na ordem de 36\% para os PD e 24\% para PED. Na quantidade de exportações beneficiadas ficou estabelecido o corte de 21\% para PD e 14\% para os PED (PABIS,2015; PIMENTA JÚNIOR, 2012).

Sobre o apoio interno, questão mais sensível, ficou acordado que os subsídios deveriam ser categorizados de acordo com o seu grau de distorção. A alocação por cores serviria para garantir fins de organização. A caixa amarela abarca medidas internas que mais prejudicam o comércio, garantindo seu caráter mais distorcivo e exigindo a redução gradual de 20\% para PD e 13\% para PED, abrangem políticas de preço mínimo, créditos de custeio, investimento e comercialização, isenções fiscais e pagamentos complementares. As caixas azul e verde não apresentam compromisso de redução gradual, classificadas como de mínima distorção e não distorcivo, respectivamente. Como balanço geral do Acordo, vale ressaltar que Países de Menor Desenvolvimento Relativo (PMDR) ficaram isentos de aplicar qualquer redução, os prazos para efetivação dos cortes foi de 6 anos para PD e 10 anos para os PED, a Cláusula de Paz que restringia por 9 anos o uso do Órgão de Solução de Controvérsias (OSC) para questões de subsídios agrícolas foi acordada, restringiu-se a adoção de medidas compensatórias e novas negociações deveriam ocorrer 1 ano antes do período de implementação, ou seja, em 2000 (PIMENTA JÚNIOR, 2012; RAMANZINI JÚNIOR e LIMA, 2011).

Com o fim eminente da Cláusula de Paz, os anos 2000 prometiam para a OMC o lançamento da primeira rodada que adentrasse mais diretamente questões ligadas a desenvolvimento e agricultura nos termos dos PED. O impacto deixado pelo ataque às torres gêmeas nos Estados Unidos e o início de uma interpretação de combate à pobreza atrelado ao combate ao terrorismo traçaram as condições iniciais para uma mudança na interpretação da relevância dos temas dentro do cenário multilateral. As negociações se deram a partir de coalizões, prática que já vinha se consolidando como benéfica para países em desenvolvimento dentro do seio do regime mediante duas questões. A primeira é a oportunidade de encontrar na ação coletiva a possibilidade de 
aumentar os custos de uma possível represália de atores mais fortes dentro do seio das negociações. A segunda consiste na facilitação da divisão do trabalho e troca de informações entre os membros, melhorando as capacidades de representação dessas nações (NARLIKAR, 2012; PEET, 2009; RAMANZINI JÚNIOR e LIMA, 2011; WILKINSON, 2016).

A criação do G2o comercial se deu na conferência ministerial de Cancun. Composto por Argentina, Bolívia, Brasil, Índia, China, Chile, Colômbia, Costa Rica, Cuba, Equador, El Salvador, Guatemala, México, Paquistão, Paraguai, Peru, Filipinas, África do Sul, Tailândia, Venezuela, Egito e Quênia, teve seu reconhecimento oficial em dezembro de 2003, após uma reunião dos membros em Brasília. O grupo ficou conhecido por conseguir balizar interesses sobre liberalização agrícola de ordem mais defensiva e agressiva, ou seja, as demandas dos grupos Cairns $^{2}$ e $\mathrm{G}_{3} 3^{3}$ estariam contempladas na agenda muito bem formulada e ativa desse grupo. Por abrigar uma grande parcela dos países em desenvolvimento e menos desenvolvidos, tendo em sua composição, inclusive, os três maiores líderes emergentes (Brasil, Índia e China), a ação dessa coalizão não poderia passar despercebida pelo antigo Quad (EUA, UE, Japão e Canadá). Além disso, o grupo respondia por 60\% da população mundial, 70\% da população rural mundial e 26\% das exportações agrícolas, o que, aliado a uma boa coordenação e conhecimento técnico, garantiria à coalizão grande poder de voz no seio das próximas negociações (NARLIKAR e TUSSIE, 2004; PABIS, 2015; PIMENTA JÚNIOR, 2012; RAMANZINI e VIANA, 2012; WILKINSON, 2014b).

Ao todo, a Rodada Doha foi composta por quatro reuniões ministeriais: Cancun (2003), Genebra (2004), Hong Kong (2005) e Genebra (2008). Foi nesta última em que ocorreu o famoso deadlock da questão agrícola com a dissensão do G20 e a construção de um novo cenário em que o Brasil se alinhou à proposta dos norte-americanos e europeus. Iniciada com a Conferência de Cancun, no México, dois grandes dilemas estavam postos, iniciar ou não as negociações sobre questões de Cingapura ${ }^{4}$ e balizar as diferentes visões sobre agricultura. No que se refere às questões

${ }^{2}$ Grupo criado em 1986, na cidade de Cairns na Austrália. Composto por Argentina, Austrália, Brasil, Canadá, Chile Colômbia, Filipinas, Hungria, Indonésia, Malásia, Nova Zelândia, Tailândia e Uruguai, tinha como objetivos incluir efetivamente o tema da agricultura na agenda da rodada do Uruguai do GATT, maior liberalização do comércio de produtos agrícolas e a redução dos subsídios a exportação. A coalizão se desfez com o final das negociações e fechamento do Acordo Agrícola.

3 Grupo dos países que defendia práticas mais defensivas para a agricultura ligada a mecanismos de salvaguarda e o estabelecimento de produtos especiais que se colocassem a exceção das tarifarias acordadas no seio da instituição. Eram eles: Antígua e Barbuda, Barbados, Belize, Benim, Bolívia, Botsuana, China, Congo, Costa do Marfim, Cuba, Dominica, República Dominicana, Equador, El Salvador, Granada, Guatemala, Guiana, Haiti, Honduras, Índia, Indonésia, Jamaica, Quênia, Coréia do Sul, Madagáscar, Maurícia, Mongólia, Moçambique, Nicarágua, Nigéria, Paquistão, Panamá, Filipinas, São Cristóvão e Névis, Santa Lúcia, São Vicente e Granadinas, Senegal, Sri Lanka, Suriname, Taiwan, Tanzânia, Trindade e Tobago, Turquia, Uganda, Venezuela, Zâmbia, Zimbábue.

4 Os chamados temas de Cingapura consistem em quatro grandes questões levantadas na conferência de 1996 em Cingapura. Pontos como investimento, concorrência, facilitação comercial e compras governamentais representaram pautas de muita importância para atores como Estados Unidos e União Europeia. No que concerne a investimento e concorrência, defendia-se que as duas questões estariam diretamente correlacionadas e deveriam ser negociadas de forma mais ampla, a base de consenso e considerando conhecimentos técnicos já auferidos pela sociedade internacional, perdendo seu caráter específico como era 
de Cingapura, muita resistência foi encontrada por parte dos países em desenvolvimento para que essa agenda evoluísse. Coalizões formadas por esses países ganharam fôlego a fim de garantir que suas demandas passassem no seio das negociações e fizessem frente ao tradicional Quad 5 (NARLIKAR e TUSSIE, 2004).

Na tentativa de emitir uma declaração ministerial, em agosto de 2003, três grandes propostas surgiram em Cancun. A dos Estados Unidos junto à União Europeia, outra do Presidente do Conselho Geral da OMC, e outra do G20 comercial. A proposta dos primeiros previa uma continuidade nos subsídios à exportação, manutenção da caixa azul, ausência regulatória da caixa verde, redução tarifária que não contemplava as particularidades dos $\mathrm{PED}$, adiamento do prazo de discussão da reforma agrícola e a tentativa de desmembrar esses últimos ao visar à criação de uma nova categoria de países, os Net Food Exporting Countries. A proposta do Presidente do Conselho Geral também foi pelo mesmo caminho. O grande rechaço do G20 a essas propostas encontrou grande resistência dos componentes do Quad. Entre as propostas desse grupo estavam a eliminação da caixa azul de subsídios, maior regulação da caixa verde, eliminação das salvaguardas para os PD, criação de um mecanismo de salvaguarda para os PED e outro para a inserção de produtos especiais para sofrer menores reduções tarifárias e a eliminação completa de subsídios às exportações (CARVALHO, 2010; PIMENTA JÚNIOR, 2012; WILKINSON, 2004).

O resultado final dessas discussões acabou favorecendo mais uma vez a atuação dos países mais desenvolvidos com a adoção em última hora das questões de Cingapura na declaração ministerial. Muito se discutia que a principal questão a ser imposta no documento final para futuras negociações seria a agricultura, reconhecido até por atores como Estados Unidos e União Europeia. No entanto, a adição dos temas de Cingapura representou, segundo Narlikar e Tussie (2004), um instrumento estratégico para tentar desarticular o G2o e a união entre PED e países com menor desenvolvimento relativo. No entanto, a unidade não foi afetada e os comprometimentos do grupo mantiveram-se firmes e fortes para uma futura conferência, tendo como resultado apenas a saída de 5 negociadores: Colômbia, Costa Rica, Peru, El Salvador e Guatemala.

A oficialização do G20 como coalizão negociadora da OMC se deu em dezembro do mesmo ano em um encontro das delegações dos países em Brasília. Conforme discurso do então presidente brasileiro Luís Inácio Lula da Silva, o compromisso do G2o seria:

(...) A força do G20 reside em seu compromisso com um mandato negociador da rodada de Doha, em suas propostas construtivas e em sua legitimidade política.

feito anteriormente. A facilitação comercial agiria de forma a garantir mais responsividade a instituição com o reforço da transparência das transações e cotas tarifárias, ou seja, assegurando melhor qualidade da informação. Por último, no que cerne as compras governamentais, defendia-se a modificação de acordos plurilaterais para a esfera multilateral, visando garantir maior transparência e assegurar o princípio da não discriminação (WTO, 2015).

5 O termo "Quad tradicional" é utilizado para se referir as grandes potências negociadoras responsáveis por delinear os principais termos e resultados das negociações. São eles: Estados Unidos, União Europeia, Japão e Canadá. 
Nossos países representam mais de 22\% da produção agrícola mundial e neles vivem mais de 70\% dos agricultores do mundo. Os países do Grupo respondem por cerca de $60 \%$ da população do planeta. Imbuído dessa legitimidade e representatividade, o G20 está mudando a dinâmica da diplomacia comercial multilateral, graças a firmeza da atuação individual de seus membros e de sua visão coletiva, o G2o tem contribuído para que os parâmetros de discussão da questão agrícola na OMC deixem de ser impostos pelos interesses protecionistas de alguns poucos atores (...). (MINISTÉRIO DAS RELAÇÕES EXTERIORES, 2007, pp. 65 e 66).

Em agosto de 2004, movidos pelo interesse em evitar repetir o impasse deixado pela conferência de Cancun, durante uma reunião em Genebra, chegou-se à conclusão de que apenas um tema de Cingapura seria levado adiante, o tópico de facilitação comercial. As negociações em questões agrícolas se seguiram entre os principais países interessados, eram eles: Brasil, Índia, Austrália, Estados Unidos e União Europeia. Entre os objetivos desse encontro estava selar possíveis metas para a próxima conferência ministerial e fechar o chamado "Pacote de Julho". Os interessados estavam imbuídos a se comprometer em eliminar os subsídios a exportação e condicionantes para ajuda alimentar, limitar os gastos da caixa azul para $5 \%$ do total de produções agrícolas e redução dos gastos em minimis (montante mínimo de suporte doméstico permitido), além da adoção de um mecanismo de corte tarifário por camadas, no qual tarifas mais altas sofrem cortes mais profundos, inclusão do tratamento especial diferenciado, exceções para países menos desenvolvidos e um acordo para que todos os países possam escolher um produto para ser tratado como especial. Em contrapartida, algumas questões ainda ficaram em aberto como data limite para corte dos subsídios e o estabelecimento de um sistema de salvaguardas especiais (COSKERAN, KIM e NARLIKAR, 2012; PEET, 2009).

Com objetivos parcialmente premeditados pela reunião em Genebra, a conferência ministerial de Hong Kong inicia-se em dezembro de 2005 e foi caracterizada por apresentar resultados ambíguos para a questão agrícola. No que concerne a data estipulada para o fim dos subsídios as exportações dos PD, ficou acordado o ano de 2013. Inicialmente o G20, com a participação do Brasil, teria sugerido o ano de 2010, mas em virtude de protestos de atores como a União Europeia, 2013 acabou constituindo a data final. Esse avanço é questionável, pois os subsídios as exportações constituíam o menor dos males. Todavia, os elementos considerados mais distorcivos ao comércio agrícola internacional, os subsídios internos, contentou-se com propostas vagas e ainda em aberto (WILKINSON, 2006).

A questão do acesso aos mercados caracterizou-se como eixo mais sensível para a negociação. A garantia dos mecanismos de salvaguarda e produtos especiais não representava consenso dentro do próprio G20, diante de o mesmo cooptar países com diretrizes mais ofensivas rumo à liberalização, como Brasil e Argentina com fortes interesses competitivos e agronegócio robusto, e também ser composto de nações com propósitos mais defensivos, como Índia, China e Indonésia com vastas áreas de agricultura familiar e população rural. A oficialização desses mecanismos trouxe resultados mistos para a coalizão que compunha membros dos Cairns e G33 e contribuiu, de certa 
forma, até para o acirramento de fragilidades entre os membros do G20. A discussão de tais temas se deu de forma mais acalorada em 2006 (RAMANZINI JÚNIOR, 2012).

O apelo em defesa da unidade do grupo, no entanto, não deixou de fazer parte da marca discursiva brasileira nas negociações. Conforme exposto em carta aos chefes de governo dos países que compunham o G20 em 2005, o presidente Lula defendia:

\begin{abstract}
Tenho para mim que o papel desempenhado pelo G2o, desde sua criação em agosto de 2003, tem sido instrumental para os progressos alcançados até o presente e para dar-nos esperança de que o resultado final recompensará todo o esforço feito. O G2O firmou-se, amadureceu e fortaleceu-se a ponto de constituir hoje referência central no processo de negociações agrícolas na OMC. Em Cancun, pudemos neutralizar propostas de países desenvolvidos que não atendiam as nossas preocupações. $\mathrm{Na}$ negociação do chamado "Acordo Quadro", de julho de 2004, nossos interesses foram incorporados ao mandato negociador. Estou convencido, mais do que nunca, que somente a unidade do G2o poderá garantir que, nesse momento crucial, nossos interesses sejam bem considerados e que a Rodada seja bem-sucedida. Devemos reforçar a unidade do Grupo e sua capacidade de resposta frente às tentativas que, estou certo, se sucederão para dividi-lo e enfraquecê-lo. Precisamos também estar atentos aos interesses dos países menos desenvolvidos e devemos trabalhar no sentido de procurar estabelecer soluções criativas que levem ao aumento de suas receitas exportadoras, sem criar dependências como as que hoje subsistem. Escrevi recentemente a vários líderes europeus, salientando a disposição brasileira de contribuir efetivamente para tal (MINISTÉRIO DAS RELAÇÕES EXTERIORES, 2007, pp. 189 e 190).
\end{abstract}

Em meio a um cenário de poucas esperanças para o avanço nas negociações sobre agricultura, uma reunião em julho de 2008 para o lançamento de um novo pacote encontrou polvoroso otimismo entre os negociadores. Questões como acesso a mercado e subsídios internos finalmente entrariam no acordo que traria números e metas diferenciadas para países desenvolvidos e em desenvolvimento. Os demandantes agrícolas estavam com altas expectativas para ver o fechamento de uma Rodada que já se alastrava por 7 anos. Para a agricultura, o pacote proposto por Pascal Lamy na miniministerial de 2008 deveria garantir o consenso dos 7 grandes demandantes, EUA, Austrália, Índia, UE, Japão, China e Brasil, e previa: manutenção da meta para 2013 do corte de subsídios a exportação; evitar a criação de subsídios disfarçado com novos mecanismos; cortes significativos ao apoio doméstico em uma margem acima de 70\% para países desenvolvidos e entre 50 e 60\% para países em desenvolvimento com validade de 5 anos para os primeiros e 8 para os últimos; sobre o acesso aos mercados, os países desenvolvidos deveriam cortar 70\% de suas tarifas mais altas e poderiam designar até $4 \%$ de seus produtos como sensíveis, os PED em contrapartida, poderiam designar 12\% (GONÇALVES, 2015; INOCALLA, 2013).

Uma questão que vinha ganhando mais relevância já em fins de 2006 foi responsável por comprometer o bom resultado esperado por atores como Estados Unidos e União Europeia no início da reunião. Os mecanismos de salvaguarda especiais passaram a ser instrumento de principal barganha para países como Índia, China e Indonésia e não eram vistos com muito entusiasmo por países como Austrália e Brasil. Segundo o pacote de Lamy, esses mecanismos poderiam ser 
acionados caso houvesse um surto de 40\% de importação de um produto agrícola específico. Esse resultado foi visto de forma bastante benéfica por negociadores como Brasil, UE, EUA e Austrália, no entanto, as nações do G33 enxergaram esses números como um desaforo. Estratégias para tentar derrubar esses precedentes aconteceram por diversas vias, incluindo a formação de uma contraproposta apresentada pela Índia, que diminuiria esse número para 10\% (COSKERAN, KIM e NARLIKAR, 2012; PEET, 2009).

A negação da proposta indiana por parte dos Estados Unidos e União Europeia e o favorecimento do Brasil ao "Pacote de 2008" contribuíram para o enfraquecimento do poder de coesão do G20 e postergar o fim da Rodada, que apresenta impasse para as questões agrícolas até os dias atuais. Vale salientar também que a crise estourada em fins de 2008 começou a adquirir dimensões estratosféricas. A crescente descrença da esfera multilateral como meio de negociação dessas questões essenciais para o desenvolvimento passou a ser uma constante, aliado a um ambiente de cada vez mais resistência por parte de países desenvolvidos em ceder às liberalizações agrícolas, deixando Doha cada vez mais distante de sua tônica proposta (INOCALLA, 2013).

Embora não tenham sido alcançados os resultados esperados na rodada, o Brasil em muito se beneficiou das exportações agrícolas facilitadas com seu alinhamento junto às potências emergentes Índia e China. A valorização da política comercial se comprova, portanto, ao se analisar os dados sobre crescimento dos superávits agrícolas na balança comercial ao mesmo tempo em que os discursos brasileiros em foros multilaterais se alinhavam à defesa do setor. Os efeitos desse posicionamento são melhor elucidados quando se analisa o impacto sobre a demanda agregada e decisões políticas tomadas pelo governo Lula para a promoção de políticas públicas voltadas para o social, amparadas pela menor restrição externa. Tais questões serão trabalhadas na seção a seguir.

\section{GOVERNO LULA E O SEU "MILAGRINHO ECONÔMICO"}

O período que deu início à primeira década dos anos 2000 ficou marcado pelos imensos saltos de crescimento da economia chinesa. Seu impacto para o comércio internacional é refletido na alta demanda por commodities minerais e agrícolas, tendo como maior consequência à valorização dos preços dessas mercadorias. As economias latino-americanas surfaram bem nessa "onda de sorte", visto que se inserem historicamente no cenário internacional como exportadores de produtos primários, e alcançaram crescimentos econômicos significativos bem como resultados positivos no combate às desigualdades (BIANCARELLI, 2014). Tais condições, no entanto, não explicam a totalidade do que se convencionou chamar de "Milagrinho" na economia brasileira. O que o governo Lula (2003-2010) traz de novo nessa equação consiste na conexão direta entre crescimento econômico e demandas sociais para a formulação de suas decisões políticas macroeconômicas (CARVALHO, 2018). 
O ineditismo na história brasileira de um desenvolvimento econômico aliado a avanços sociais tem feito com que muitos autores defendessem a inauguração de um novo desenvolvimentismo denominado "desenvolvimentismo social" para explicar o governo Lula. Em seu primeiro ano, no entanto, o complicado cenário deixado pelas eleições e a opção pela continuidade de antigas decisões macroeconômicas herdadas do governo anterior orientadas ao controle da inflação e redução da dívida pública contribuiu para que o crescimento alcançado no ano de 2003 não correspondesse às expectativas nutridas, marcando apenas 1,1\%. A manutenção do tripé, que incluía a defesa de metas de superávit primário, de inflação e câmbio flutuante, trouxe uma orientação restritiva no primeiro momento, situação esta que se reverteria no ano seguinte puxada por um novo otimismo no cenário internacional e conquista da confiança dos investidores para o novo governo (BIANCARELLI, 2014).

Em seus 3 primeiros anos, os avanços sociais alcançados pela administração petista basearam-se em muito na criação de um programa de transferência de renda denominado Bolsa Família, responsável por uma redução significativa nos índices de pobreza e desigualdade social no país. Estima-se que a parcela de famílias que viviam abaixo da linha de pobreza caiu de $28,1 \%$ em 2003 para 15,3\% em 2009. No que cerne a extrema pobreza, os números são igualmente impressionantes, marcou 11,3\% em 2003 e chegou a 5,8\% em 2009 (CACCIAMALI e TATEI, 2016). Tais feitos, no entanto, são resultado de uma nova orientação econômica inaugurada em 2006 e levada adiante até o final de seu segundo mandato. O chamado "Milagrinho" representou uma nova fase do crescimento brasileiro que, proporcionado pela bonança da grande entrada de divisas via comércio, permitiu estabelecer um desenvolvimento puxado pelo mercado interno (CARVALHO, 2018).

O pagamento da dívida externa com o FMI ainda em 2005, graças aos superávits comerciais das commodities, garantiu também maior autonomia para decisões políticas sobre política fiscal do governo Lula. O "Milagrinho" consistiu em um momento de largo crescimento econômico aliado à ampliação do consumo e dos investimentos públicos, acesso ao crédito e distribuição de renda para as camadas sociais menos favorecidas. A valorização mais acentuada do salário mínimo, junto aos programas de transferência de renda, contribuiu em muito para que isso fosse possível, elevando a participação de setores que demandava uma mão de obra menos qualificada, como o setor de serviços e construção civil, nesse processo de fortalecimento do mercado interno (SICSÚ, 2019).

O lançamento do Programa de Aceleração do Crescimento (PAC) após a reeleição de Lula, em 2007, marcou a forte expansão dos investimentos públicos em território nacional. O foco do programa se colocou sobre a infraestrutura física e social, estando em primeiro lugar a área de energia, em segundo, o setor de habitação e saneamento e, em terceiro, as áreas ligadas à infraestrutura logística, relacionadas a rodovias, ferrovias, aeroportos, hidrovias e portos. Além de ter criado um enorme montante de empregos e sustentado a geração de renda mesmo diante da grande crise de 2008/2009, o programa impactou também na atração de investimentos privados, 
uma vez que ao dinamizar o mercado interno se recuperam as expectativas das empresas sobre demandas futuras. Dessa forma, ao apresentar um efeito multiplicador mais significante, os investimentos públicos têm maior potencial de induzir outros investimentos, gerar emprego, aumentar renda e, consequentemente, ampliar o consumo (CARVALHO, 2018).

Outras duas circunstâncias importantes para explicar a bonança do mercado interno no governo Lula consiste na ampliação do acesso ao crédito e formalização do mercado de trabalho. No que cerne ao primeiro, a introdução do crédito consignado garantiu aos indivíduos trabalhadores e aposentados o acesso a crédito com taxas de juros mais baixas e prazos maiores. Como sua expansão se deu junto ao crescimento do emprego e da renda, os endividamentos não chegaram a ser problema para a economia naquele período. Sobre a formalização do mercado de trabalho, o período do "Milagrinho" foi capaz de ir de encontro a diversas teorias que postulavam a defesa de menos direitos e maior grau de informalidade para garantir um aumento crescente no número de empregos. Amparado por um largo crescimento gerado pelas commodities e dinamização do mercado interno, a arrecadação de impostos acompanhou essa tendência e contribuiu para arcar com maiores investimentos e gastos públicos sem provocar danos às metas de superávit primário (CACCIAMALI e TATEI, 2016).

A vulnerabilidade da economia brasileira em relação ao cenário internacional também foi diminuída com o impacto das entradas de divisas via comércio de commodities e fortalecimento do mercado interno. Os efeitos de uma possível depreciação brusca da moeda brasileira frente ao dólar traziam consequências quase contrárias daquelas observadas nos anos 1990. A desvalorização do real significava o aumento do valor das nossas reservas cambiais, uma vez que diante da quase ausência de dívida externa significaria uma redução da dívida líquida do governo. Tal situação ajudou a amenizar as forças catastróficas da crise de 2008/2009. Sobre os juros, embora tivesse se mantido entre os mais altos do mundo, houve uma redução significativa da Selic entre 2005 e 2007. O controle da inflação se deu em função do dólar baixo. A entrada de um grande fluxo de capital via comércio ajudou a manter o real valorizado, tornando as importações menos custosas, ao mesmo tempo em que ocorria o boom nas exportações em virtude da demanda chinesa (CARVALHO, 2018).

Entre os principais limites do "Milagrinho" estava a baixa competitividade e fragilidade do setor industrial. Tal situação se acentuou ainda mais no pós-crise de 2008, evidenciando ainda mais o descolamento do crescimento entre comércio e indústria. Com as facilidades do dólar baixo e superávits gigantescos na balança comercial, o volume de importações quase duplicou. Logo, aliado a isso, a apreciação cambial do real trouxe o efeito de desestimular os investimentos para impulsionar diferentes setores industriais, trazendo assim, as condições para caracterizar o que se denominou de "Doença Holandesa” para explicar os vastos crescimentos alcançados no período. Os setores de serviço e construção civil, por outro lado, ao absorver um grande percentual de mão de obra pouco qualificada também contribuiu para que o crescimento do mercado interno não fosse acompanhado pelo processo de desenvolvimento de uma matriz produtiva mais diversificada, 
encontrando seus limites no próprio cenário externo que possibilitou uma mudança gradual nas políticas macroeconômicas. Com o início de uma tendência de queda nos preços das commodities a partir de 2012, os impactos do "Milagrinho" começam a ser revertidos e a economia brasileira nunca mais conseguiu voltar aos patamares de crescimento alcançados no período (SILVA e LOURENÇO, 2014; OREIRO e FEIJÓ, 2010).

\section{CONSIDERAÇÕES FINAIS}

A primeira década dos anos 2000 ficou marcada pelo alcance de um vasto crescimento da economia brasileira liderada pela administração do governo Lula (2003-2010). Os impactos dos grandes aumentos nos preços das commodities e os direcionamentos frente a uma balança comercial favorável se consolidaram como as principais condições para garantir a sobrevivência desse processo. O efeito do cenário externo favorável serviu de pano de fundo para o novo direcionamento das políticas macroeconômicas baseadas na dinamização do mercado interno liderado pelo aumento dos investimentos públicos e estímulo ao consumo.

Os saltos de crescimento no PIB agrícola e os grandes aumentos de superávit na balança comercial do setor representam umas das marcas distintivas do período para explicar o processo de valorização do real frente ao dólar. A valorização do setor, no entanto, não se deu apenas pelos indicadores econômicos. A bandeira da liberalização e expansão do comércio agrícola foi marca distintiva do governo Lula na atuação da diplomacia comercial brasileira frente aos foros multilaterais internacionais. O caso da Rodada Doha, na Organização Mundial do Comércio, ilustra bem essa temática.

Iniciada em 2003 com a conferência de Cancun, a Rodada Doha não alcançou os objetivos brasileiros junto à histórica coalizão de países em desenvolvimento e menos desenvolvidos, o G20 comercial. No entanto, a aproximação com as outras duas grandes potências emergentes da época, Índia e China, garantiu ao Brasil importantes vantagens comerciais e dinamização de seu mercado doméstico a partir da cooperação incentivada. Os interesses protecionistas ainda defendidos pelos países desenvolvidos não chegaram a enfraquecer de fato a balança comercial brasileira, permitindo que, ainda em 2006, se iniciasse um novo direcionamento macroeconômico no governo Lula conhecido por "Milagrinho".

O chamado "Milagrinho" se baseou em políticas vinculadas à expansão do acesso ao crédito aliada aos maiores investimentos públicos no setor de infraestrutura física e social, bem como ao estímulo ao consumo via valorização do salário mínimo e crescente formalização do mercado de trabalho. O pagamento da dívida externa com o FMI, ainda em 2005, permitiu que o Brasil tirasse a "corda do pescoço" e pudesse inovar sem o peso de uma grande restrição externa em sua política 
fiscal. O grande volume de divisas que entrou via comércio internacional e a formação de reservas cambiais sustentaram esse processo que se solidificou com a dinamização do mercado interno.

Tal processo, no entanto, não se colocou de forma muito benéfica para o setor industrial. $\mathrm{O}$ processo de valorização cambial sustentada pela grande entrada de divisas em função da alta nos preços das commodities favoreceu o barateamento das importações que quase duplicaram seu volume no período. Os incentivos ao investimento no setor industrial dessa forma ficaram desfavorecidos, tendo em vista também que a dinamização do mercado interno se deu em grande medida pela expansão do setor de serviços e construção civil, que demandavam por uma mão de obra pouco qualificada.

Por desfavorecer a diversificação da matriz produtiva, ao não incentivar investimentos para ramos industriais distantes do setor agroexportador, o ensinamento deixado pelo "Milagrinho" é que uma mudança real na economia deve se basear no desenvolvimento de setores com maior capacidade de transformação. Somente eles são capazes de gerar uma verdadeira autonomia e se tornar mais sustentável diante das vulnerabilidades do sistema internacional. Um indicativo disso é que, a partir de 2012, frente à mudança da bonança externa com as commodities, o Brasil não conseguiu mais sustentar os mesmos resultados.

*Artigo recebido em o5 de agosto de 2020, aprovado em 25 de outubro de 2020.

\section{REFERÊNCIAS}

BIANCARELLI, André M. A Era Lula e sua questão econômica principal: crescimento, mercado interno e distribuição de renda. Revista do Instituto de Estudos Brasileiros, n. 58, pp. 263288, 2014.

CACCIAMALI, Maria Cristina; TATEI, Fabio. Mercado de trabalho: da euforia do ciclo expansivo e de inclusão social à frustração da recessão econômica. Estudos avançados, v. 30, n. 87, p. 103121, 2016.

CARVALHO, Laura. Valsa Brasileira: do boom ao caos econômico. São Paulo: Todavia, $1^{\text {a }}$ Ed., 2018.

CARVALHO, M. I. V. Condicionantes Internacionais e Domésticos: o Brasil e G2o nas Negociações Agrícolas da Rodada Doha. Revista de Ciências Sociais, Rio de Janeiro, v. 53, nº 2 , PP. 405-445, 2010.

COSKERAN, Helen; KIM, Dan; NARLIKAR, Amrita. "Trade in manufactures and agricultural products: the dangerous link?”. In: DAUTION, Martin; NARLIKAR, Amrita; STERN, Robert M. (Org.). The Oxford Handbook on the World Trade Organization. New York: Oxford University Press Inc., 2012. 
GONÇALVES, P. T. C. Os "jogos ocultos" do brasil e o impasse na OMC: uma análise das negociações multilaterais de comercio de 2008. 2015. 124 f. Tese (Doutorado em Ciência Política) - Instituto de Filosofia e Ciências Humanas, Universidade Estadual de Campinas, Campinas. 2015 .

INOCALLA, Ganesh. A participação do Brasil nas negociações agrícolas da Rodada Doha da OMC na era Lula (2003-2010): uma análise da coerência entre os princípios gerais da política externa e a atuação do Brasil. 2013. 154 f. Dissertação (Mestrado em Relações Internacionais) - Instituto de Relações Internacionais, Universidade de Brasília, Brasília, 2013.

MINISTÉRIO DAS RELAÇÕES EXTERIORES. G-2o e a OMC: Textos, Comunicados e Documentos. Brasília: Fundação Alexandre de Gusmão, 2007.

NARLIKAR, Amrita e TUSSIE, Diana. The G2o at the Cancum Ministerial: developing coalitions in tne WTO. Oxford and Buenos Aires. Blackwell Publishing Ltd, 2004.

NARLIKAR, Amrita. "Collective Agency, Systemic Consequences: Bargaining Coalitions in the WTO”. In: DAUTION, Martin; NARLIKAR, Amrita; STERN, Robert M. (Org.). The Oxford Handbook on the World Trade Organization. New York: Oxford University Press Inc., 2012.

OREIRO, José Luis; FEIJÓ, Carmem A. Desindustrialização: conceituação, causas, efeitos e o caso brasileiro. Brazilian Journal of Political Economy, v. 3o, n. 2, p. 219-232, 2010.

PABIS, Jonatas Luis. "Acorrentando Gúlliver: a atuação dos BRICS nas negociações sobre agricultura da Rodada Doha da OMC". In Anuario Mexicano de Derecho Internacional, v.15, n.1, pp. 659-699, 2015.

PEET, Richad. “The World Trade Organization”. In: Unholy Trinity: IMF, World Bank and the WTO. Nova York: PalgraveMacmillan, 2009.

PIMENTA JÚNIOR, José Luiz. Coalizões Internacionais e o G-2o: aspectos da liderança brasileira na rodada Doha de desenvolvimento na OMC. 2012. Dissertação (Mestrado em Relações Internacionais) - Instituto de Relações Internacionais, Universidade de São Paulo, São Paulo, 2012.

RAMANZINI JÚNIOR, Haroldo; LIMA, Thiago. "Diplomacia comercial agrícola: as posições do Brasil na Rodada Doha da OMC". In. AYERBE, Luis Fernando; BOJIKIAN, Neusa Maria Pereira (Orgs.). Negociações Econômicas Internacionais: Abordagens, atores e perspectivas desde o Brasil. São Paulo: Editora UNESP, 2011.

RAMANZINI JUNIOR, Haroldo; VIANA, Manuela Trindade. Países em desenvolvimento em uma ordem internacional em transformação: coalizões e soluções de disputas na OMC. Revista Brasileira de Política Internacional, Brasília, vol. 55, nº 2, PP. 48-69, 2012.

RAMAZINI JÚNIOR, Haroldo. O Brasil e as negociações no sistema GATT/OMC: uma análise da Rodada do Uruguai e da Rodada Doha. 2012. Tese (Doutorado em Ciência Política) - Faculdade de Filosofia, Letras e Ciências Humanas, Universidade de São Paulo, São Paulo, 2012.

SERRANO, Franklin; SUMMA, Ricardo. Demanda agregada e a desaceleração do crescimento econômico brasileiro de 2011-2014. Nova Economia, v. 25, pp. 803-833, 2015.

SICSÚ, João. Governos Lula: a era do consumo? BrazilianJournalofPoliticalEconomy/Revista de Economia Política, v. 39, n. 1, pp. 128-151, 2019. 
SILVA, José Alderir da; LOURENÇO, André Luís Cabral de. Restrição Externa: A Economia Brasileira na Década Recente e o Modelo de Thirlwall. Revista Economia \& Tecnologia, v. 10, n. 4, pp.9-35, 2014.

SILVA, L. A. F. da; CUNHA, Marcelo Pereira da. Preço internacional das Commodities e impactos na atividade econômica brasileira: Simulações por equilíbrio geral computável. Revista ESPACIOS, v. 37, n. 30, pp. 29-46, 2016.

SILVA, L. A. F. da; LOPREATO, F. L. C. Comércio internacional brasileiro: Considerações para os setores industriais e de commodities. Revista ESPACIOS, v. 38 n.9, pp. 10-23, 2017.

WASQUES, Renato Nataniel; TRINTIN, Jaime Graciano. "Doença Holandesa”: aspectos teóricos e evidências empíricas para a economia brasileira. Revista de Estudos Sociais, v. 20, n. 41, pp. 160-186, 2018.

WILKINSON, Rorden. Crisis in Cancun. Global Governance, v. 10, n. 2, p. 149-155, 2004.

WILKINSON, Rorden. The WTO in Hong Kong: what it really means for the Doha Development Agenda. New Political Economy, v. 11, n. 2, p. 291-304, 2006.

WILKINSON, Rorden. What's Wrong with the WTO and How to Fix It. John Wiley \& Sons, 2014a.

WILKINSON, Rorden ."Emerging powers and the Governance of Global Trade". In. PAYNE, A. J.; PHILliPS, N. (Orgs.). The Handbook of the International Political Economy of Governance. Cheltenham: Edward Elgar, 2014b.

WILKINSON, Rorden. Conclusions: Emerging Powers in the WTO-Beware the Glass Ceiling. International Negotiation, v. 21, n. 2, p. 327-341, 2016. 